$\operatorname{Cocos}(1997), 12,44$ - 53

Printed in Sri Lanka.

\title{
ALTERNATIVE METHODS TO DETERMINE PLOT SIZES FOR TREE CROPS: \\ A CASE STUDY FROM COCONUT DATA
}

\author{
T S G Peiris ' and R O Thattil '
}

I Coconut Research Institute, Lunuwila, Sri Lanka

2 Department of Crop Science, Peradeniya University,

Peradeniya, Sri Lanka

\section{SUMMARY}

Two methodologies are proposed to determine the most efficient plot size for tree crops using data from experiments based on randomized complete block designs. Both methods can be generalized for data from any balanced design. The merits and demerits of these methods are discussed. The methods are illustrated using the data sets of long-term field experiments at the Coconut Research Institute, Sri Lanka. The results show that efficient plot size in field experiments for coconut for a wide range of agroecological regions is four or six palms.

\section{INTRODUCTION}

In field experiments the efficient testing of the treatment effects depends upon the experimental precision. One way of increasing efficiency is to use optimum plot and block sizes to maximize the information obtained for each rupee of money spent. The size and shape of plots as well as blocks are usually determined by evaluating uniformity trials over a long period. These trials are expensive to perform and need large extent of land. Consequently the optimum plot size has not been thoroughly studied for many tree crops, particularly for coconut.

The Coconut Research Institute of Sri Lanka (CRISL) conducts, annually, on the average, $10-15$ long-term field experiments in different fields 
of specialty to improve coconut cultivation. Considering the nature of the experiments at the CRISL and the yield variation between palms, randomized complete block designs have been commonly used.

Pieris and Salgado (1937) suggested 16 - 18 palms per plot which occupies nearly 0.1 ha per plot. This is not economical in many circumstances. On the assumption of biennial bearing of tree crops Abeywardena (1964) suggested a minimum plot size of six palms to reduce the biennial fluctuation. Abeysinghe (1986) recommended that a plot size of four palms could be used for completely randomized design (CRD) experiments if the two year pooled pre-experimental yield can be used as a covariate in the analysis. This approach is not flexible as data for the previous two years for the experimental site are not always available. These studies were based on single sets of data. Further, as yield of coconut fluctuates with changes in climate and weather the investigation of plot sizes for different agro-ecological regions of Sri Lanka is necessary.

Pearce (1978) stated that, "the resident biometrician should look back over completed experiments to see how things have turned out, not from the point of view of agronomic results but of biometrical efficacy".

Two methods are proposed here to decide on the most efficient plot size for any tree crop using the past data from any balanced design experiment. The methods are illustrated using two sets of coconut data conducted at two different agro-ecological regions of Sri Lanka by the Coconut Research Institute (CRI).

\section{METHODOLOGY I}

Let $Y_{i j k}$ be the response variable (yield) of the $k^{\text {th }}(k=1,2, \ldots . . n)$ palm (experimental unit) in the $i^{\text {th }}(i=1, \ldots . . b)$ block of the $j^{\text {th }}(j=1, \ldots . . . t)$ treatment where $\mathrm{n}$ is the number of palms per plot (that is, plot size). In a randomized complete block design (RCBD) the number of treatments are equal to the number of plots within a block and the treatments are randomly allocated among plot within a block. $Y_{i j k}$ can be written as;

$$
Y_{i j k}=\mu+\beta_{i}+\tau_{j}+\varepsilon_{i j}+\rho_{i j k}
$$

Where $\beta_{i}=$ effect of the $\mathrm{i}^{\text {th }}$ block, $\tau_{j}=$ effect of the $\mathrm{j}^{\text {th }}$ treatment, $\varepsilon_{\mathrm{ij}}=$ random variability (experimental error), $\rho_{\mathrm{ijk}}=$ random variability (palm to palm within plots) and $\mu$ is the overall effect. $\varepsilon_{i j}$ can be assumed to be inde- 
pendent and distributed as $N\left(0, \sigma^{2} e\right), \rho_{i j k}$ can be assumed to be independent and distributed as $N\left(0, \sigma^{2} \rho\right)$. The general analysis of variance table (ANOVA) of the model (1) is given in Table 1.

Table 1. General analysis of variance table under model (1)

source of degrees of sums of mean

variation freedom squares squares

Between blocks

b-1

SSB

MSB

Between treatments

$t-1$

SST

MST

Experimental error

$(b-1)(t-1)$

SSEE

MSEE

Plot total

bt-1

SSPT

MSPT

Palms within plots

$(\mathrm{n}-1) \mathrm{bt}$

SSSE

MSSE

(Sub-sampling error)

Total

nbt -1

SSTT

SSPT $=($ SSB + SST + SSEE $)$ and SSTT $=($ SSPT + SSSE $)$. If $Y . .=\Sigma_{1} \sum_{j} \Sigma_{k} Y_{i j k} / b t n$ then the coefficient of variation for the experiment, $C V$ is given by,

$$
\mathrm{CV}=\frac{\sqrt{\mathrm{MSEE}}}{\mathrm{Y} . .} * 100
$$

The method involves calculating the coefficient of variation for new plots of different sizes and observe at which 'point' the CV stabilized. As $\mathrm{Y}_{\mathrm{ijk}}$ 's have treatment effect and block effect, plot sizes are chosen from the palms within a plot. To choose identical plot shape the palms within a plot are numbered in the same sequence from one to $\mathrm{n}$ (see Appendix A). For each plot size and plot shape the MSEE and Y... are computed. In choosing plots the following steps can be adopted. 
1. All palms numbered $I$ in each plot are used to calculate $C V$ of plot size one.This is repeated separately for all palms within plot numbered from 2 to $n$. The average of these $n$ CV's is taken as the CV of plot size of one.

2. The number of palms per plot is now increased to 2 , by selecting palm numbers 1 and 2 from each plot to form plot size of two. All the possible combinations of each plot size of two are selected from each of the original plots such that if a particular pair of numbers is selected from plot 1 , then the same numbers are selected from the remaining plots. Thus there are $n(n-1) / 2$ separate analysis for ${ }^{-} \mathrm{CV}$ for plot size of two. The average of these $n(n-1) / 2$ CV's is taken to represent the $\mathrm{CV}$ of plots of size two.

3. The above procedure is repeated for plots of size 3 to $n$.

4. The average CV's are plotted against the plot size. The plot size at which $\dot{C} V$ values stabilized is taken as the most efficient plot size.

\section{METHODOLOGY II}

In a typical uniformity trial the model is

$$
Y_{i}=\mu t+\varepsilon_{i}
$$

Therefore from the observed values $Y_{i j k}$ the treatment effect and the block effect are removed to make the model (1) comparable to model (3). When those effects are removed the ensuing yields can be treated as if they come from a uniformity trial. If $\mathbf{X}_{\mathrm{ijk}}$ is the yield after removing the treatment and block effects then,

$$
\begin{aligned}
& X_{\mathrm{ijk}}=Y_{\mathrm{ijk}}-\left(\mu+\beta_{\mathrm{i}}+\tau_{\mathrm{j}}\right) \\
& -\cdot=Y_{i j k}-Y_{\ldots-}-\left(Y_{i . .}-. Y_{\ldots}\right)-\left(Y_{j}-Y_{\ldots} \ldots\right) \\
& =Y_{i j k}-Y_{i . .}-Y_{j .}+Y . .
\end{aligned}
$$

where $Y_{i . .}=\Sigma_{j} \Sigma_{k} Y_{i j k} / t n, Y_{j .}=\Sigma_{i} \Sigma_{k} Y_{i j k} / b n s$, and $Y_{\ldots}=\Sigma_{i j} \Sigma_{j} \Sigma_{k} Y_{i j k} / b t n$. The $X_{i j k}$ 's can bé consideted as $Y_{i}(i=1,2,3, \ldots \ldots . ., b t n)$ and can be analyzed using Fairfield Smith's technique (Smith, 1938). This technique has been widely used to find the plot sizes for different crops using data from uniformity trials. The Fairfield Smith's techniques is briefly explained here. 
Different plot sizes from 1 to $\mathrm{n}$ are selected from the initial field plan. Palms are selected across the rows and columns so that the shape of plots are rectangular or square. When there are $N_{x}$ plots of size $x(1 \leq x \leq n)$ with yield $Y_{x}$ per plot then the coefficient of variation $\mathrm{CV}_{\mathrm{x}}$ is

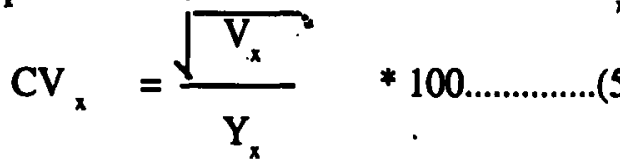

Where $V_{x}$ is the variance of plots of size $x$ and $Y_{x}$ is the mean of plots of size $x$. Thus by calculating $\mathrm{CV}_{\mathrm{x}}$ for different plot sizes the most efficient plot size is obtained from the plot of $\mathrm{CV}_{\mathrm{x}}$ vs $\mathrm{x}$.

The shape of the plots and blocks is usually decided by the nature of the experiment and the area of the land available. However, rectangular and square plots are generally preferable for tree crops. Method II can be used to study the plot shape and block, but method I has some limitations to tackle this problem as plots are selected within the pre-defined plot. Another disadvantage of method I is that the maximum number of plot size has to be restricted to the initial plot size of the experiment.

Both methods showed that the optimum plot size is not affected by the number of plots. In RCBD number of plots are equal to the number of treatments irrespective of the plot size. In our analyses the effect of the guard rows were not considered and hence the cost associated with the palms in the guard rows does not arise. Guards rows are generally not recommended for the experiments in coconut palms except intercropping trials because there is no fertilizer movement between palms. But, the guard rows can be considered if required under both methods.

\section{APPLICATION OF THE TWO METHODS}

\section{Secondary Data}

The yield data (1985-87) for this study were obtained from two longterm field experiments conducted in low country region of the intermediate zone $(75 \%$ expectancy of annual rainfall $>1800 \mathrm{~mm})$ and dry zone $(75 \%$ expectancy of annual rainfall $>1500 \mathrm{~mm}$ ) by CRISL. The design of both experiments was RCBD.

Experiment 1 was to study the effect of incorporating coir dust on the physical condition of the soil structure. It had five treatments and five blocks 
and each block consists of five plots of eight palms. Experiment 2 was to compare the effects of three frequencies of ploughing and two depths with an unploughed control treatment on a sandy soil. It had seven treatments and four blocks and each block consists of seven plots of nine palms.

The field plan of each experiment is shown in Appendix A. Further details can be found in CRI (1985). The two methods were applied to each set of data on yearly basis.

\section{Use of Method I}

As explained above the possible rectangular and square shape plots were selected. The plot size was varied from one to eight in data set 1 and from one to nine in data set 2 . The analyses was carried out for yearly data and the mean CV was taken for a given plot size. The variation of mean CV for different plot sizes, of the data sets 1 \& 2 are shown in Figures $1 . a$ and 1.b respectively.

Figure 1.(a) clearly indicated that CV decreased sharply when the plot size increased from one to four in all years, but after that there was no appreciable decrease. After the plot size of six the decrease of CV is negligible. Similar trend can be seen in Figure 1.(b). Thus the efficient plot size can be taken as four or six palms without any covariates.

\section{Use of Method II}

The treatment and block effects were removed from individual paim yield on yearly basis. The experiment 1 has 10 rows of 20 palms and 20 columns of 10 palms and experiment 2 has 12 rows of 21 palms and 21 columns of 12 palms (see Appendix A). Non overlapping plots of size one to ten were selected along each row and each column. In selecting plots along -rows (or columns) a few palms at the end had to be neglected when the remaining palms were not divisible by the plot size. The mean CV for a given plot size over different combinations was computed.

The plots in Figure 2 also have the similar trend as in Figure 1 indicating that 4-6 palms per plot are sufficient in both locations with respect to coefficient of variation. It also indicates that $\mathrm{CV}$ decreased rapidly for every single palm increase from one to six. 
Table 2 shows the computed values of CV's under two methods. It can be seen that the $\mathrm{CV}$ is extremely high for plot size of one palm.

Table 2. The computed values of $\mathrm{CV}$ for the two sets of data under the two methods.

\begin{tabular}{|c|c|c|c|c|c|c|c|}
\hline \multirow[t]{2}{*}{ Method } & \multirow[t]{2}{*}{ Plot } & \multicolumn{3}{|c|}{ data set 1} & \multicolumn{3}{|c|}{ data set 2} \\
\hline & & 1985 & 1986 & 1987 & 1985 & 1986 & $198^{\circ}$ \\
\hline \multirow{9}{*}{ I } & 1 & 31.4 & 30.6 & 34.7 & 27.8 & 28.4 & \\
\hline & 2 & 20.5 & 17.7 & 22.3 & 12.4 & 14.2 & \\
\hline & 3 & 15.7 & 12.1 & 19.1 & 10.6 & 12.1 & \\
\hline & 4 & 14.8 & 10.4 & 15.5 & 10.0 & 11.7 & 11. \\
\hline & 5 & 13.8 & 9.9 & 15.2 & 9.9 & 11.6 & 11.3 \\
\hline & 6 & 13.4 & 9.7 & 14.7 & 9.7 & 11.4 & 11.2 \\
\hline & 7 & 13.2 & 9.6 & 14.2 & 9.6 & 10.6 & 10. \\
\hline & 8 & 12.9 & 9.3 & 13.9 & 9.4 & 10.3 & \\
\hline & 9 & - & - & - & 9.3 & 10.1 & 10.6 \\
\hline \multirow{10}{*}{ II } & 1 & 30.0 & 25.8 & 30.1 & 25.4 & 25.8 & 27.4 \\
\hline & 2 & 21.1 & 18.2 & 21.8 & 18.2 & 18.9 & 20.1 \\
\hline & 3 & 17.7 & 15.3 & 18.2 & 15.0 & 16.2 & 18.0 \\
\hline & 4 & 14.1 & 12.5 & 15.7 & 13.3 & 13.9 & 16.1 \\
\hline & 5 & 13.2 & 11.7 & 14.8 & 11.7 & 12.6 & 13.8 \\
\hline & 6 & .12 .0 & 11.0 & 13.4 & 10.8 & 11.8 & 13.6 \\
\hline & 7 & .11 .3 & 10.6 & 12.8 & 10.5 & 11.4 & 13.2 \\
\hline & 8 & 10.4 & 10.3 & 12.2 & 9.9 & 10.9 & 12.7 \\
\hline & 9 & 10.3 & 10.1 & 11.8 & 9.6 & 10.8 & 12.6 \\
\hline & 10 & 10.2 & 9.9 & 11.7 & 9.5 & 10.7 & 12.3 \\
\hline
\end{tabular}

\section{CONCLUSIONS}

The study showed that the two methods proposed in this paper are suitable to determine the optimum plot size for any tree crop. Thus conducting uniformity trials can be avoided if secondary data sets of the designed experiments are available. Although the examples cited in this paper were based on actual data from the RCBD, these methods can be easily extended for data from any type of balanced design.

Method II has more advantages than method I. The methodology II 

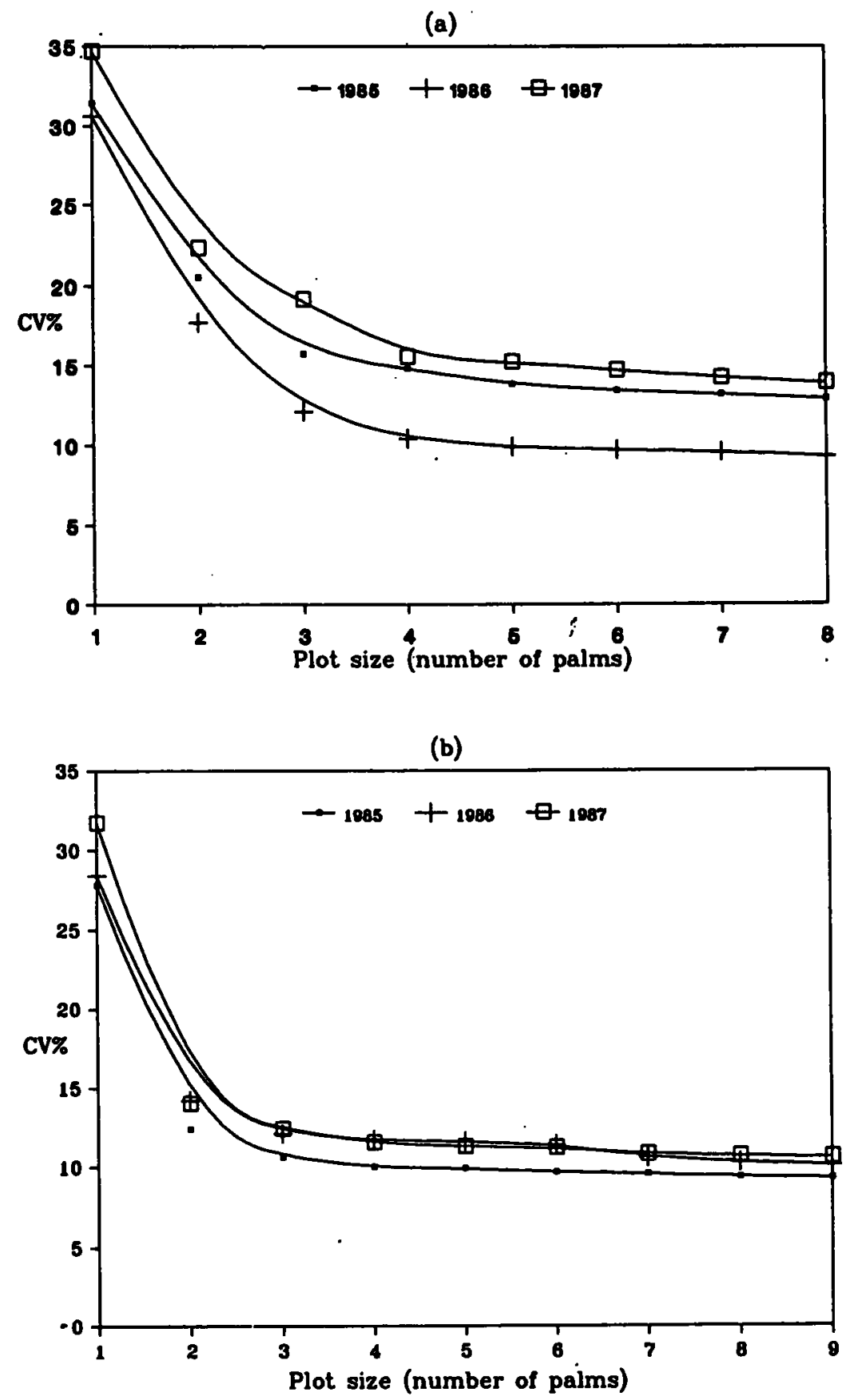

Figure 1. Relation of coefficient of variation (CV\%) to plot size based on Method I using (a) data set 1 and (b) data set 2 

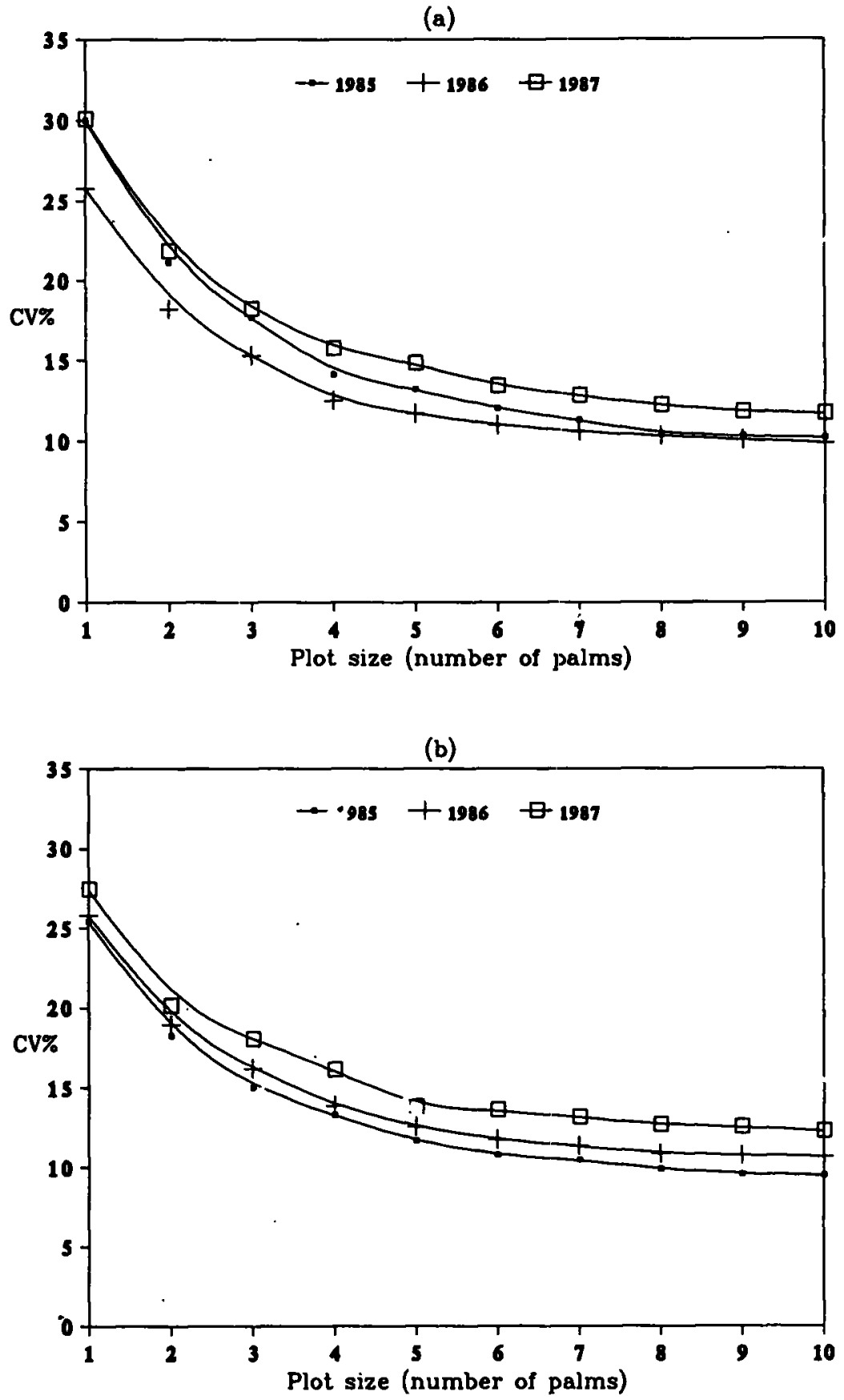

Figure 2. Relation of coefficient of variation (CV\%) to plot size based on Method II using (a) data set 1 and (b) data set 2 . 
can be used to determine the effective plot shape and block shape as well, though the standard practice in tree crop trials is rectangular. plots. As the uniformity trial data are very useful in agricultural research the benefits of such data can be obtained by removing the appropriate effects from the secondary data using the model (4). The data from a typical uniformity trial strictly speaking is valid only in the specific location in which the trail is conducted. Thus when the past data are available uniformity trials need not be repeated for different locations.

Since the data used in this study were in different agro-ecological regions, the plot size of four or six palms is recommended in field experiments for coconut irrespective of the location without the use of pre-data as covariate. Based un the pattern of $\mathrm{CV}$ in Figures 1 and 2, single palm plots are not recommended in any field experiments for coconut.

\section{ACKNOWLEDGEMENTS}

We are grateful to the Heads of Soils $\&$ Plant Nutrition and Agronomy Divisions of the CRISL, for permitting the use their experimental data.

\section{REFERENCES}

Abeysinghe Thilak (1986). Calibration of experiments on perennial crops using covariance analysis: the case of coconut. Experimental Agriculture, 22 : 353 - 361:

Abeywardena, V. (1962). Studies on biennial bearing tendency in coconut A minimum plot size for coconut. Ceylon Coconut Quarterly, 15:109 -14

CRI (1985). Report of the Coconut Research Institute for 1985 (Ed. R Mahindapala), Lunuwila, Sri Lanka.

Pearce, S.C. (1983). The Agricultural field experiment - A statistical examination of theory and practice. John Willey and Sons Ltd, New York, 293 pp.

Peiris, W. V. D. and Salgado, M. L. M. (1937). Experimental error in field experiments with coconut. Trop. Agriculture, Trinidad, 89:75-85.

Smith, H.F. (1938). An empirical law describing heterogeneity in the yields of agricultural crops. J. of Agric. Science, Cambridge, 28:1-23. 